\title{
Florida Patient Safety and Pre-Suit Mediation Program for Medical Malpractice Claims: 13-Year Results, COVID-19 Pandemic Implications, Future Innovations, and Blueprint for Nationwide Implementation
}

Randall C. Jenkins*, Esq., Daniel J. D’Alesio Jr. Esq., Stephanie C. Gann, B.S. University of Florida J. Hillis Miller Health Center Self-Insurance Program, United States.

Article Details
Article Type: Research Article
Received date: $25^{\text {th }}$ November 2021
Accepted date: $30^{\text {th }}$ December, 2021
Published date: $03^{\text {rd }}$ January, 2022
Corresponding Author: Daniel J. D'Alesio Jr. Esq., Senior Litigation Attorney, University of Florida J. Hillis Miller Health
Center Self-Insurance Program, United States. E-mail: dalesiod@sip.ufl.edu
Citation: Jenkins, R.C., Jr. Esq., D.J.D.A., \& Gann, S.C. (2022). Florida Patient Safety and Pre-Suit Mediation Program
for Medical Malpractice Claims: 13-Year Results, COVID-19 Pandemic Implications, Future Innovations, and Blueprint for
Nationwide Implementation. J Pub Health Issue Pract $6(1): 193$. doi: https://doi.org/10.33790/jphip1100193
Copyright: C2022, This is an open-access article distributed under the terms of the Creative Commons Attribution License
$\underline{4.0, \text { which permits unrestricted use, distribution, and reproduction in any medium, provided the original author and source }}$
are credited.

\section{Abstract}

In 2008, the University of Florida Health system (UF Health) created the Florida Patient Safety and Pre-Suit Mediation Program (FLPSMP) to complement UF Health's patient experience and loss prevention initiatives. The FLPSMP was designed to timely compensate patients for meritorious medical malpractice claims, reduce frivolous lawsuits, and facilitate early, effective communication between patients and their health care providers and health care facilities, with the benefits of confidential mediation conducted by court-certified experienced medical professional liability mediators. In its first five years, " $[\mathrm{T}]$ he program resulted in faster resolution of claims, lower legal expenses, and greater compensation to patients with meritorious claims [1]." After eight years, the FLPSMP continued to demonstrate the benefits of significantly reduced claim receipt-to-resolution times, substantial reduction in defendant legal expenses, and increased net proportionate recovery by claimants, compared to recovery through litigation [2]. This article updates the data to include the first 13 years of the FLPSMP, of which 12 occurred prior to the onset of the COVID-19 outbreak. Additionally, the authors explain the helpful provisions of mediation law in Florida that support the FLPSMP, discuss the impact of the COVID-19 pandemic on the FLPSMP results, report the perspectives of mediators who participate in the program, and recommend the FLPSMP as a blueprint for expansion nationwide as an alternative dispute resolution model. The analysis continues to demonstrate the positive impact of the program in of expense, uncertainty, and delays of protracted litigation for all parties, and settlements with a better net outcome for claimants.

\section{Introduction}

The High Economic and Societal Costs of Traditional Medical Malpractice Litigation litigation process costs more than $\$ 55.6$ billion annually (in 2008 dollars) [3]. The U.S. Chamber Institute for Legal Reform Lawsuit Climate Survey in 2019 ranked states in terms of overall treatment of tort and contract litigation, damages, trial judges' impartiality and competence, jury fairness, and proportional discovery, and ranks Florida among the five worse states in these categories [4]. The high financial risk of professional liability claims for hospitals as well as providing a fair platform for swift resolution of claims, reduction

According to Mello et al, the traditional medical malpractice

health care providers in Florida, especially South Florida (MiamiDade, Broward, and Palm Beach counties) is evident in the 2020 Aon Risk Solutions (Aon) and American Society for Healthcare Risk Management (ASHRM) benchmark analysis. Indemnity payment per closed claim in South Florida, for example, over the five year period of 2015 - 2019, was the highest in the nation, averaging $\$ 496,000$ per claim, while cost of defense in South Florida over the same period averaged $\$ 119,000$, also the highest in the nation [5]. Florida's overall loss rate per occupied bed equivalent increased steadily from 2008 through 2015 when it was at $\$ 8,190$, almost three times the national average [6]. Since 2015, the loss rate continued to increase, with South Florida having the highest rate projected for the state at $\$ 11,340$ [7]. Florida's costly medical malpractice litigation experience and unfriendly state liability system is not an isolated experience. Similar negative experiences occur in states from all areas of the country, such as West Virginia, Mississippi, California, Louisiana, and Illinois, New York, and New Jersey, and Missouri [8].

All cases in litigation generate costs and fees born by both parties prior to final resolution. Indemnity payments made by defendants and their insurers, as a result of judgments or settlements, and allocated loss expenses (cost of litigation) run high for defendants, especially if the litigation is pursued over a long period of time prior to resolution. Conversely, claimant's costs of litigating the case over a protracted period of time can be significant, including costs of retaining experts, court reporting transcription, records production, and other related costs of litigation. Coupled with contingent fees of the attorneys, these costs not only erode the net economic recovery for claimants if finally successful in litigation, but also increase the total "value" of the case, making it impractical, at times, for both sides to settle in advance of a jury verdict. Some estimates, for example, show that "for every dollar spent on compensation, 54 cents went to administrative expenses (including those involving lawyers, experts, and courts). Claims involving errors accounted for 78 percent of total administrative costs."'[9]

The pure economic costs, however, are not the only costs that take a toll on the parties. Defendant health care providers and claimants alike suffer emotional distraught during the course of litigation, while never being assured of success or satisfactory closure during years of litigation. During the long course of litigation, injured claimants may not have adequate health insurance or other assets to assist them 
in managing their medical costs and requirements of daily living, thereby increasing their psychological stress. Defendant health care providers also suffer emotional distress during years of litigation when they must endure allegations of negligence and assertions that their alleged malpractice injured or killed their patients, thereby negatively affecting their personal lives and their health care practice.

Focused risk analysis, along with loss prevention and claims mitigation practices, such as addressing patient grievances in a timely manner, appropriate apologies, billing write-offs, thorough investigation of incidents, and improved medical and nursing practices and protocols, are very helpful in attempting to resolve medical negligence claims and disputes at early stages. By incorporating presuit mediation agreements into the consent and authorization process in 2008, UF Health added an additional structural component that makes the FLPSMP an effective, cost-effective program to further reduce the economic and noneconomic costs of traditional litigation. As this article details in the data analysis of the FLPSMP's first 13 years, the program significantly reduced the time to resolve medical malpractice disputes, resulted in more net financial recovery to patients with meritorious claims, and substantially reduced legal expenses for all parties by providing a process and platform for early, efficient, and effective communication for patients, health care providers, and health care facilities participating in the FLPSMP.

\section{The Florida Patient Safety and Pre-Suit Mediation \\ Program}

Historical Beginnings and Purpose: On January 1, 2008, the FLPSMP went into effect at the University of Florida Health Science Centers in Gainesville and Jacksonville, Florida, which consist of six colleges within the UF Health system (Dentistry, Medicine, Nursing, Pharmacy, Public Health, and Veterinary Medicine), the two UF Health teaching hospitals (UF Health Shands Hospital in Gainesville and UF Health Jacksonville Medical Center), the UF Health clinics, physicians, physician practices, institutes, centers, programs, and support services [10]. From the outset, "FLPSMP was designed to meet three objectives - compensate deserving patients in a fair and timely manner; facilitate accurate and timely providerpatient communication (including patient safety improvements when identified); and reduce frivolous lawsuits—as well as associated costs and expenses for all parties [11]." The FLPSMP uses experienced inhouse counsel and claims examiners from UF Health in the pre-suit process to help reduce the costs of the program.

Florida Mediation Infrastructure Conducive to Implementation of the FLPSMP: Florida mediation law has the procedural and substantive provisions that support the success of the FLPSMP. Although it has not adopted the Uniform Mediation Act, the Florida Mediation Confidentiality and Privilege Act created checks and balances in Florida law that provide essential elements to encourage and promote success in civil mediations by protecting mediation communications from disclosure, establishing certification criteria for mediators, providing immunity for mediators, and also by establishing a code of ethics for certified mediators along with disciplinary sanctions for breaches of the ethical rules [12].

FLPSMP mediation communications are confidential and may not be disclosed to any person other than a mediation participant or his or her counsel [13]. The mediator certification process provides reassuring standards of mediator education, training, mentorship, and good moral character. Mediators must complete an approved mediation certification course and must possess a graduate degree, complete a mentorship program, including mediation observations or supervised mediations with a certified mediator, and must possess good moral character [14]. Specific mediator standards of conduct are also codified in rules promulgated by the Florida Supreme Court [15].

Mediation communications are inadmissible in court [16], with limited exceptions [17]. Mediators also enjoy a degree of mediator immunity provided by Section 44.107(2), Florida Statutes. While a certified mediator can be grieved for failing to meet the standards of professional conduct for mediators, mediators "have immunity from liability arising from the performance of that person's duties while acting within the scope of the mediation function" unless the mediator "acts in bad faith, with malicious purpose, or in a manner exhibiting wanton and willful disregard of human rights, safety, or property [18]." This immunity protection enhances mediators' effectiveness in assisting parties who are embroiled or potentially may be embroiled in litigation.

Patient Agreement to Mediate: Patients enter into the FLPSMP at admission to a UF Health facility (hospital admission or clinic visit), at which time they sign a pre-suit mediation agreement as part of the consent and authorization process. The documentation includes the agreement to mediate in language the same or similar to:

- Agreement to Mediate-In accepting care at this facility where UF employees and/or agents provide medical care and treatment, I agree that before I file any lawsuit for medical care and treatment rendered by its health care providers, I will first attempt to resolve my claim through confidential mediation. Mediation is a process through which a neutral third party who has been certified to be a mediator tries to help settle claims. UF Health will pay the cost of the mediator. I further agree that any mediation must take place in the state and county where my treatment was rendered, unless all parties agree otherwise. This agreement is binding on me and any entity or individual making a claim on my behalf. This agreement does not waive my right to file a lawsuit if the mediation process fails to resolve my claim. I understand that lawsuits must be filed within a certain time period and that the time for me to file a lawsuit is not extended as a result of my participation in mediation [19].

The FLPSMP Process and Rationale: As is true in all jurisdictions, mediation in Florida is an alternative dispute resolution process in which parties can attempt to resolve their issues with the objective of obtaining closure by using the services of a qualified mediator to facilitate communication and understanding between the parties. In the authors' decades of collective experience, successful mediation is attained when the parties come to understanding about what meets the "needs" of the parties to resolve the contested issues, rather than what the parties "think they want" to resolve their disputes. The mediator serves as the experienced, neutral and impartial facilitator, while the parties remain the only decision makers. Florida laws favor mediation, and mandates in-person mediation in litigation cases within 120 days after a law suit commences [20]. This mediationfriendly environment in Florida discussed previously was a catalyst in the development of the FLPSMP. Parties engaging in the FLPSMP participate in pre-suit mediation with the protections of confidentiality, and the hospital / provider defendants, either personally or through their representatives, have an opportunity to speak directly and candidly to the claimants, months and sometimes years earlier than would otherwise be the case in court-ordered mediation or in non-confidential depositions during the litigation process. Patients participating in FLPSMP mediations bear no mediator costs; the FLPSMP pays the full mediator fee for all mediation participants. The FLPSMP uses experienced in-house counsel and claims examiners in the pre-suit process, which reduces the costs to the UF Health system and helps make the program financially feasible.

The FLPSMP does not restrict the right of access to the courts to pursue traditional litigation if mediation is unsuccessful. The FLPSMP, instead, provides an earlier and less-costly mechanism for the parties to attempt to better understand the strengths and weaknesses of their respective positions and try to reconcile their differences without the economic and non-economic burdens of costly, prolonged, litigation, without assurances of either party having their needs met. 
Using a confidential setting that encourages open dialogue between patients and their health care providers, the FLPSMP creates early opportunities for patients and health care providers to resolve their disputes in a process over which they have control of the resolution at mediation. This process is contrasted with engaging in a long litigation journey in which high litigation costs are likely to reduce patients' net recovery for injuries sustained, health care providers and their insurers bear very high defense costs, and the ultimate resolution of the matter will be left up to a vote of strangers empaneled on a jury, and appeals courts.

The primary reason patients become plaintiffs pursuing medical malpractice claims through the court system is the breakdown in the health care provider-patient relationship due to unsatisfactory or faulty communication [21]. The need for an explanation about why an injury occurred, rather than just a desire for compensation, often becomes the major motivation for patients to pursue litigation to obtain those answers [21]. Even when unanticipated or disappointing outcomes occur, a provider's objective, compassionate, and sincere communication about them with the patients involved reduces the likelihood of litigation and can mitigate the cost of the claim if one is made [22]. The FLPSMP serves as a structured and more comfortable venue for patients and health care providers to exchange information, face-to-face, in a frank and candid manner, under the legal cloak of confidentiality, before either party becomes inextricably entrenched in their positions, and before accumulated costs become an obstacle in themselves to resolve the dispute.

\section{Effects of the COVID-19 Pandemic on the FLPSMP}

Emergency Orders / Legislation Granting Immunities: During the COVID-19 pandemic restrictions, the FLPSMP continued by participating in virtual pre-suit mediations, using Zoom or other similar remote meeting programs. While many virtual mediations involve claims that predate the pandemic, the complex interplay of the unique federal and state pandemic-related laws related to healthcare providers highlight the high value of the FLPSMP for healthcare dispute resolutions. For example, on March 10, 2020, the federal Public Readiness and Emergency Preparedness (PREP) Act provided immunity to protected entities (certain individuals and entities) that manufacture, develop, test, administer, and dispense COVID-19 countermeasures [23]. The countermeasures include a variety of medications, vaccines, and therapeutics, as well as diagnostic testing and devices related to detection, prevention, cure and mitigation of COVID-19 [23]. Do these federal protections sufficiently cover state licensed healthcare providers? Because healthcare professional liability claims are governed differently state by state, some states have issued legislation providing liability immunity to persons and entities providing health care services in response to COVID-19 as long as the allegations were not willful or gross negligence. Not all states, however, have enacted state-specific COVID-19 liability protections for healthcare individuals or entities, and not all states which have enacted COVID-19 liability immunity provide the same level of protection or duration of protection [24]. These questions will take courts years to resolve. Therefore, healthcare providers and patients have even more reason to utilize FLPSMP's systemic proven contractual process to achieve resolution without enduring years of expense, delay and uncertainty from traditional litigation. Importantly, FLPSMP results for mediations held during COVID restrictions virtually mirrored a similar success rate for those conducted in person pre-pandemic.

Court Backlog and Delay in Resolving Disputes in the Courts: To varying degrees, COVID-19 shut the doors of state and federal courts. As a result, delays caused rescheduling of trials and large backlogs of existing and new cases will cause delays of parties already in litigation to get their day in court and those filing new causes of action will have their cases delayed more than was expected in the past. The National Center for State Courts (NCSC), compiling data from 12 states, noted that that although filings of cases were down in 2020 , the backlog has increased [25]. The NCSC related that "[A]ny time the number of dispositions lag the number of case filings, the active pending caseload of the court grows. In 2020, over 144,000 cases were added to the active pending civil caseloads of the reporting states. Significantly, this is in addition to the nearly 195,000 cases added to the active pending caseloads of the reporting states in 2019 [25]." Accordingly, claimants know that recovery, if at all, will take much longer through the court system as a consequence of the COVID-19 pandemic. The FLPSMP provides an attractive vehicle for patients to assert their claims pursuant to their pre-suit mediation agreement to attempt to resolve their claims in an expeditious manner.

\section{Analysis of FLPSMP: 13 Years of Data}

Process of Analysis: The authors analyzed the data pertaining to claims managed by UF Health from January 1, 2008, to December 31,2020 . As noted in a 2014 article regarding the FLPSMP, a "claim" is defined as "a written or verbal allegation of malpractice and a request or demand for compensation against a physician or hospital employee [26]." The analysis calculates the time period for resolved claims using the FLPSMP from the date of the assertion of a claim to the date of its resolution. For the purpose of comparison, average times for assertion-of-claims to resolution-of-claims resolved using the FLPSMP over the thirteen-year period was compared to nationally-reported average claims resolution times. The success rate of the FLPSMP was assessed by comparing percentages each calendar year of total claims mediated in the program that resolved through settlement or withdrawal of the claim. Additionally, the average of allocated loss expenses (costs of litigation) on claims resolved through the FLPSMP are recorded for each of the first 13 years of the FLPSMP.

\section{Results}

High Settlement Rate of FLPSMP Mediated Claims: The FLPSMP success, as measured by the high settlement rate of FLPSMP claims during the pre-COVID pandemic, is excellent, with the vast majority of mediations resolving in settlements, either during the mediation or shortly thereafter with additional discussion and continued involvement of the mediator. During the first thirteen years of the program, mediations using the FLPSMP process had an overall average resolution rate of $74.3 \%$. This overall rate, and the rates for each specific calendar year of the program, are illustrated in Figure 1. Although the authors found no benchmarking data at the national or state level for mediation programs that operate the same as or conceptually similar to the FSPSMP, data from studies of North Carolina court-directed or court-connected mediation are helpful for comparison. In an article in 2007, reporting on a "direct observational" mediation study (permission granted by the parties to have an observer present) of the 46 medical malpractice, courtdirected mediations under the auspice of the North Carolina Superior Court Mediated Settlement Conference (MSC) program, the authors found that the settlement rate of the total cases that settled was about $23.7 \%$ [27]. The authors also noted that the overall settlement rate for all types of civil cases mediated through MSC program in North Carolina had been tracking between $50 \%$ and $60 \%$ from the inception of that program [27]. The low rate of medical malpractice cases settled by the court-directed / court-connected program in North Carolina was not surprising to the authors, because of the complexity and high economic and non-economic damages related to medical malpractice cases [27]. Conversely, the high 13-year FLPSMP settlement average, when contrasted with the relatively low settlement rates for medical malpractice in the North Carolina study and the overall percentage of settlement in all civil cases in the MSC study, is a significant indicator of the success of the FLPSMP.

Faster Resolution than Traditional Litigation: During the 13 years analyzed, claims resolved using the FLPSMP, on average, less than nine months from assertion-to-resolution by settlement, dismissal, or withdrawal of claim. As noted in Figure 2, for each individual calendar year, except for 2019 , on the average all claims mediated 
using FLPSMP resolved within a year, compared to the national average of only about 45 percent resolving within a year. The 2020 benchmark analysis produced by Aon and the American Society for Healthcare Risk Management indicates that nationwide, approximately $55 \%$ of claims resolve in more than a year, regardless of the means of resolution, with approximately $30 \%$ of all claims resolving in two to five years [28].

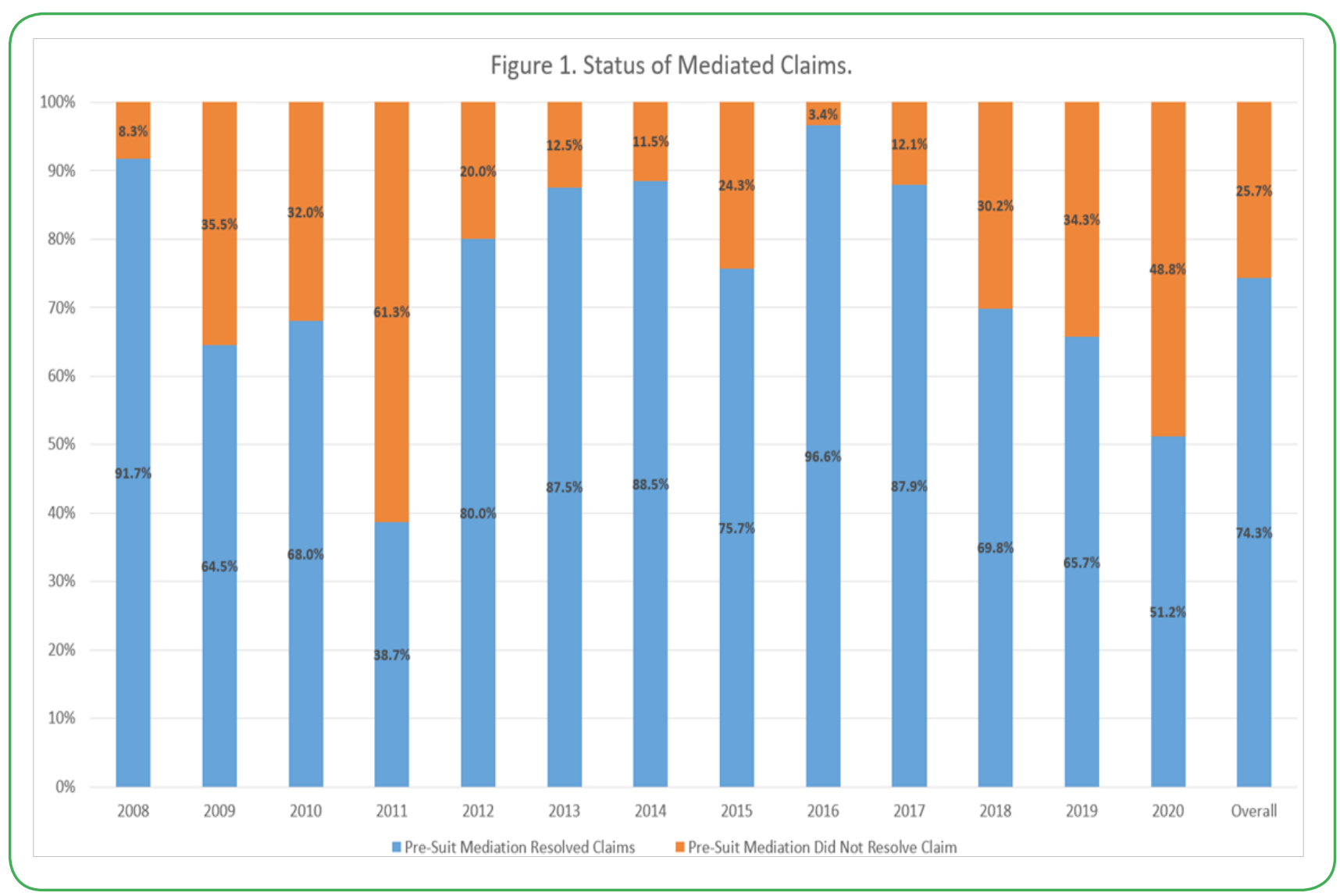

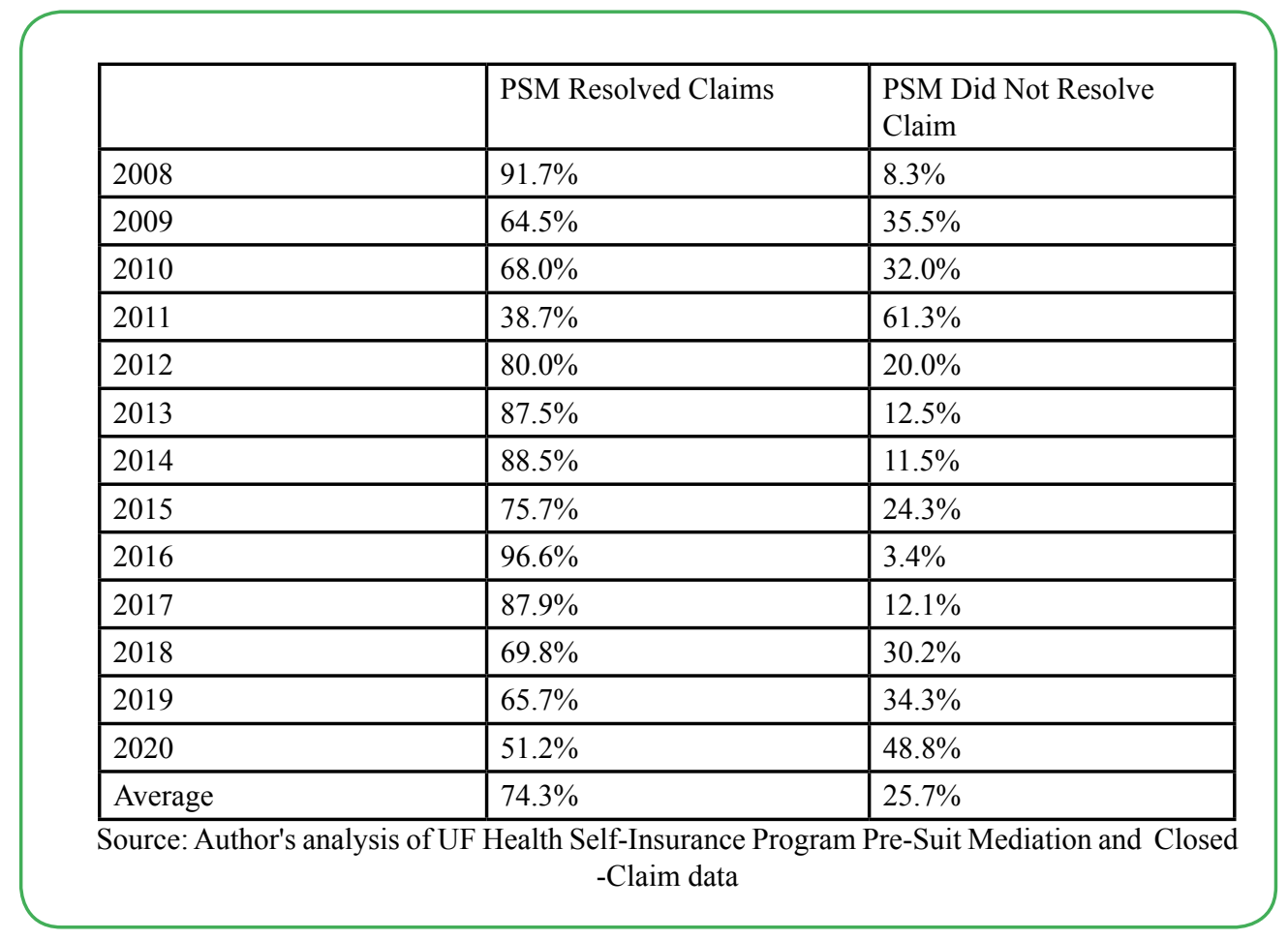

The overall resolution rate reflects the percentage of resolved claims based upon the total number of all claims mediated over the 13-year period. 


\section{Figure 2. Assert Date to Resolution.}

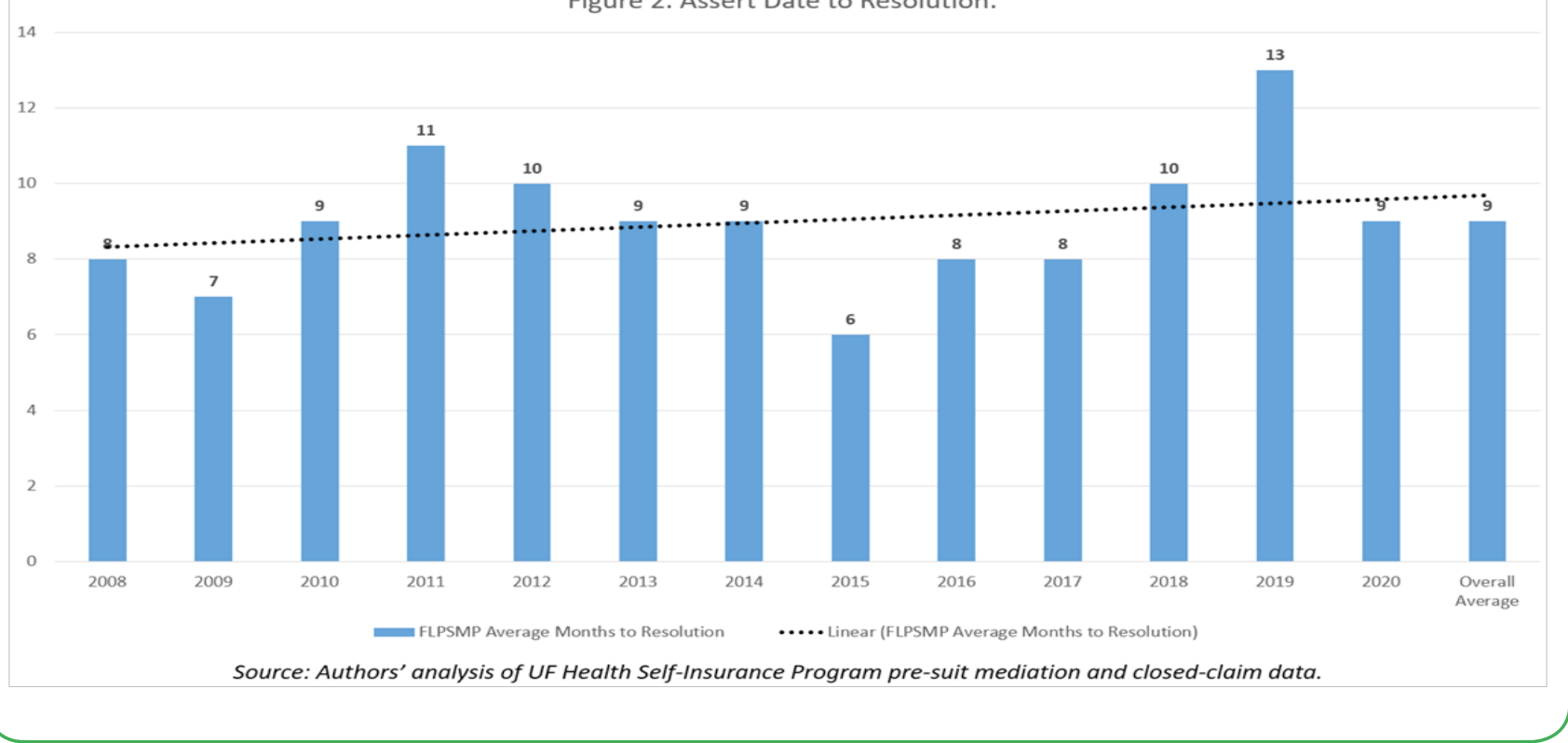

In both Figures 1 and 2, the data recorded in calendar year 2011 appears to be an outlier. In light of proposed changes of laws affecting medical malpractice claims under consideration by the Florida legislature during that year's legislative session and certain cases pending before the Florida appellate courts, plaintiffs and defendants involved in medical malpractice litigation were reluctant to settle cases because of the uncertainty of the legislative and judicial outcomes. Consequently, plaintiffs and defendants were concerned about making informed decisions concerning the benefits or detriments of settling during that time period. One of the concerns, for example, was the anticipated change that to prove that a health care provider breached the standard of care, a medical expert rendering standard of care opinions in a medical malpractice case must be of the "same" specialty as the health care provider about whom the opinion is rendered. The law before this proposed change only required the medical expert to be of a "similar" specialty [29]. Of omnibus importance to both plaintiffs and defendants was the case under consideration by the Supreme Court of the State of Florida that was taking up the issue of the constitutionality of statutory caps on pain-and-suffering damages that were still in effect in 2011 [30].

Reduced Cost of Defense: In calculating the data from the Aon reports from 2008 through 2019, the average nationwide defense legal expense over the 13-year period per settled claim was $\$ 56,750$. In Florida, as a whole, the average legal expense per claim was $\$ 85,979$ [31]. The average legal expense incurred for cases resolved through the FLPSMP, however, was only \$5,205. Figure 3 illustrates the yearly comparison of defense legal expenses for claims resolved with indemnity payments during the period of 2008 through 2019 [32] in the United States and in Florida, as compared to claims resolved through FLPSMP. During every calendar year, claims resolved through the FLPSMP incurred exceptionally low legal expenses, compared to the average costs of settlement in mediation nationwide and in the state of Florida. On average FLPSMP legal costs were $94 \%$ less than legal costs for the state of Florida as a whole and $92 \%$ less than the national average. The FLPSMP substantially reduces defense expenses, thereby focusing available funds on compensating meritorious claimants.

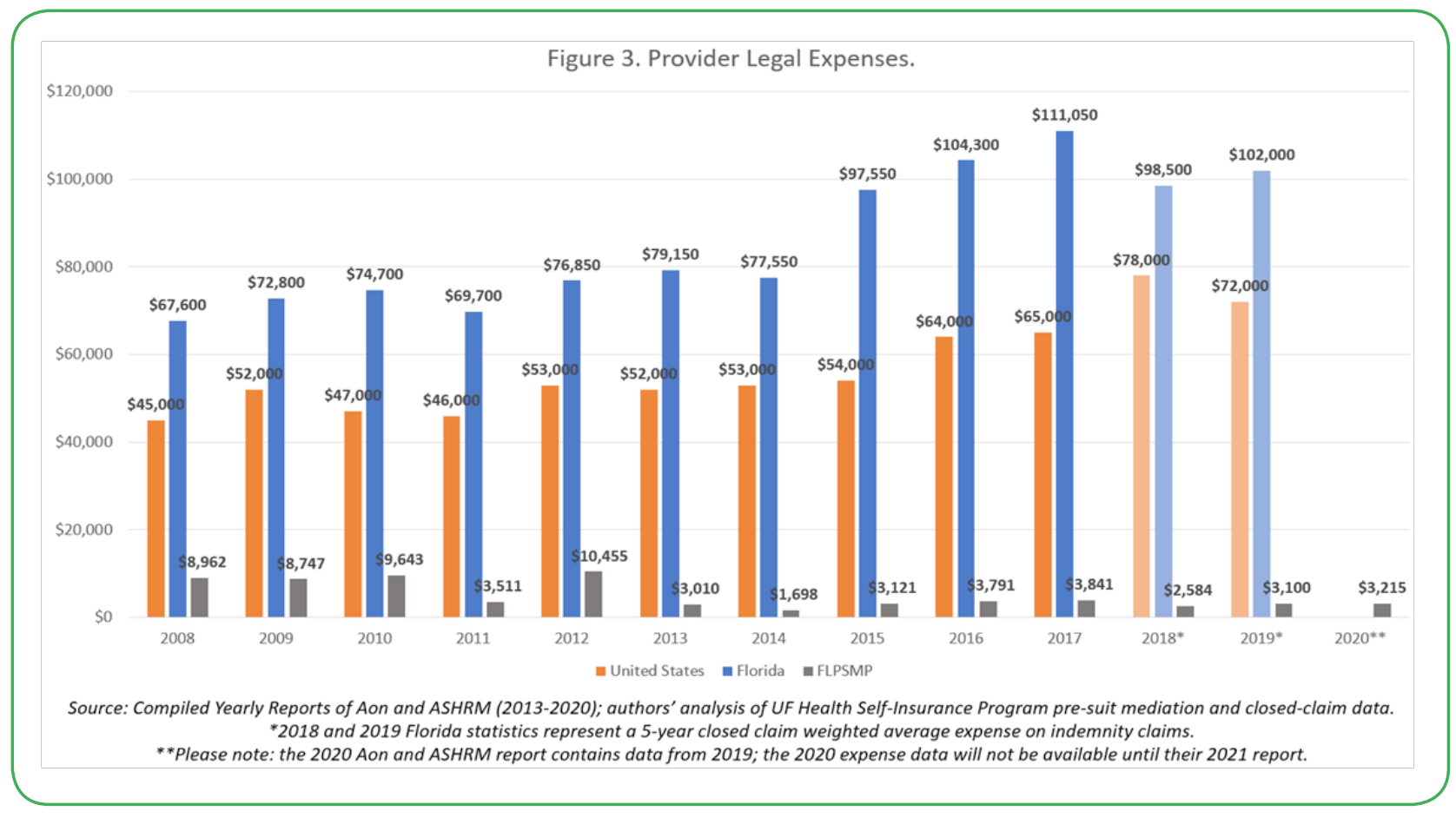


Higher Net Recovery and Less Emotional Cost for Claimants: Lower administrative costs and fees related to the defense of the case result in higher net economic recovery for patients asserting claims, by ensuring that less of any settlement payment is diminished by additional costs of litigation. Once formal litigation begins, counsel for the plaintiff, depending upon the contingency arrangement, is generally entitled to a larger percentage of a judgment or settlement than when the case settles before litigation is filed. Additionally, the FLPSMP helps bring early, emotional closure to claimants by providing a final outcome when FLPSMP mediation is successful, instead of years of emotional turmoil with the ever-present specter of defeat on the claimant's mind. In a twenty-year study of medical malpractice cases resolved by a jury, the jury verdicts in favor defendant health care providers occurred in

- $\quad \ldots 80 \%$ to $90 \%$ of the jury trials with weak evidence of medical negligence, approximately $70 \%$ of the borderline cases, and even $50 \%$ of the trials in cases with strong evidence of medical negligence. With only one exception, all of the studies of malpractice settlements also find a correlation between the odds of a settlement payment and the quality of care provided to the plaintiff. Between $80 \%$ and $90 \%$ of the claims rated as defensible are dropped or dismissed without payment. In addition, the amount paid in settlement drops as the strength of the patient's evidence weakens [33]."

As shown from the data, the expeditious, effective, confidential communication environment of the FLPSMP, along with utilizing experienced in-house counsel and claims examiners in the pre-suit process, the program provides easily available opportunities for conflict resolution between the parties. In the process, the parties avoid more burdensome financial and emotional costs of traditional multi-year litigation, where favorable outcomes are uncertain for any party until well after a jury verdict and ensuing appeals.

The FLPSMP Promotes Patient Safety and Patient Satisfaction: The FLPSMP promotes patient safety by providing health care providers and administrators the opportunity to learn more fully from incidents that expose them to potential claims, with more direct and full input from the patients concerned years earlier than during the protracted litigation system, and thereby make changes to their processes and policies to improve patient safety and avoid similar incidents and injuries to patients in the future. The speedy, nine-month average resolution time for claims mediated through the FLPSMP process, provides opportunities for open, direct, and confidential communication exchanges shared by patients, their family members and legal representatives, health care providers and health care institutions to address ways health care providers and health care systems may deliver better care. This communication augments and refines other loss prevention and process improvement initiatives that also may have been launched as a result of an incident.

Patient safety improvements can result in enhanced hospital revenue for excellent quality of care in in-patient hospital settings. The Medicare Hospital Value-Based Purchasing Program (VBP) provides "incentive payments for quality of care provided in the inpatient hospital setting [34]." As Jenkins et al. pointed out in their eight-year survey of FLPSMP results, “... one measure of quality of care recognized by the VBP is the Patient Experience of Care (PEC). PEC is a measure, in part, of patient satisfaction and PEC scores contribute to the overall value-based purchasing formula for determining reimbursement rates for hospitals. PEC measures include communication with nurses and doctors, responsiveness of hospital staff, pain management, cleanliness and quietness of the hospital environment, communication about medicines, discharge information, and the overall rating of the hospital [35]." FLPSMP's focus of open, early, productive communication to resolve claims and enhance patient safety, provides an opportunity in addition to other policies and processes in place to raise hospital PEC scores and potentially increase revenue.

\section{Additional Innovations from the FLPSMP Model}

Early Voluntary Mediation When No Agreement to Mediate Exists: In addition to the established FLPSMP mandatory presuit mediation program, in situations where no prior agreement to mediate has been executed by a claimant or by a potential codefendant, early mediation offered on a voluntary basis is helpful to resolve claims, as well as grievances that may lead to claims. The UF Health system engages in voluntary early mediation under a number of circumstances, such as: (a) visitors and business invitees to UF Health facilities who claim injury due to alleged negligence of UF Health employees or agents, will receive an offer to mediate using the same process as the FLPSMP; (b) claims in the early stages involving potential defendant health care providers or health care facilities practicing or operating outside of the UF Health system; and (c) complex and emotional grievances for which a satisfactory resolution for all parties is best served by communicating in a confidential mediation forum.

In typical visitor slip-and-fall cases and other general liability / personal injury claims, early mediation affords the health care facility an opportunity to address the liability exposure and to resolve meritorious claims with the same types of cost savings and speedier resolution experienced by using the FLPSMP process. Because there is no statutory pre-suit investigative process in Florida required for these general liability claims, early in-depth investigation is needed to optimize success at an early mediation.

In medical malpractice claims where the claimant has signed a consent to mediate, but the pre-suit evidence demonstrates that other defendants or potential defendants are outside of the UF Health System, invitations to participate in the FLPSMP with the patient and UF Health are sent to the actual or potential co-defendants. In these situations, the invitation requests them to join UF Health and the claimant in an early or pre-suit mediation. In all three of these situations, UF Health pays the mediator fees for all parties.

Grievances that may not give rise to a claim cognizable under law, but otherwise involve patient dissatisfaction or the dissatisfaction of the patient's family members regarding the delivery of care are often resolved satisfactorily by hospital and provider internal grievance policies and processes. On those occasions where there are special sensitivities for the parties, or when there are trust and credibility issues causing barriers to communication, the opportunity to conduct discussions to resolve grievances in confidential early mediation sessions with the assistance of a certified mediator may be key to the dispute resolution, especially when all mediator fees are incurred by the provider or health care facility.

Opportunities for Early Remediation and Process Improvement: Early mediation often provides opportunities to address, in a more comprehensive manner, circumstances where negligence and causation are fairly certain at the outset. Input from the patient or the patient's family at the early stages in a confidential setting with a neutral mediator, brings more diversified options to resolve the matter amicably with a more complete understanding of the effects an unexpected outcome had upon the patient and the patient's family. In some circumstances, the FLPSMP was initiated and mediation took place while the patient was still undergoing care at the institution where the incident took place. While the matters were very fresh in the memories of all involved, the facts gathered during the early investigation and additional facts learned during the communications at mediation led to expeditious assessment of the needs of the patient and the patient's family with a more satisfactory resolution, along with the initiation of improvements in patient safety.

Resolving Matters Other than Money Concerns: As is true in the mandatory FLPSMP, voluntary, early mediation facilitates the discussion of issues other than compensation, such as, offering apologies, empowering patients to speak freely in a structured mediation setting to have their questions answered and their concerns 
discussed with candor. Mediation using the FLPSMP also mitigates the tendency of providers to engage the patient in a "defensive communication mode [36]." This mode of communication is “... a mode of interaction designed to protect practitioners from malpractice suits, but which, in fact, breeds conflict and serves as a barrier to resolution efforts [37]." An early mediation setting, whether mandatory or voluntary, encourages providers and health care institutions to avoid the defensive communication mode and address with the patient the measures and counter measures that will be put into place by the provider or institution concerned to help prevent similar occurrences from happening in the future. Patients want to know and feel that the providers and institution involved in their care will learn and improve upon the things that patients believed caused their injuries and difficulties. In the authors' experiences in the FLPSMP process, patients who learn about the plans and policies that have been or will be put into effect by the providers and institutions is a significant non-monetary factor that encourages meaningful negotiations and resolution of medical malpractice claims. These positive, non-monetary benefits will occur in the FLPSMP program process well before the parties are intractably entrenched in their positions, as would likely happen, had the parties attempted to resolve the matter through a lengthy and contentious litigation journey.

\section{Further Research and Refinement}

FLPSMP Attorney and Participant Feedback: Anecdotally, over the years since FLPSMP's inception, both claimants and their attorneys who have participated in the FLPSMP process have positively voiced their support. Claimants demonstrated a preference for swift resolutions, and attorneys appear to appreciate early knowledge of substantive and procedural problems in their case, prior to making large financial outlays that would make a reasonable resolution of the case financially challenging to them and their clients. Exciting future opportunities exist to objectively measure the experiences of patients and attorney participants.

Mediator Opinions: Prior to publication, an initial survey was sent to mediators who mediated FLPSMP cases. The mediators were asked to submit their years of experience, the number of total cases mediated, and the number of FLPSMP cases mediated. For analysis, the survey results of mediators who responded and had more than five FLPSMP mediations were reviewed. This group of mediators had between 10 and 30 years of Florida Supreme Court-certified mediation experience, with a group average of just over 12 years. Collectively they participated in over 8,900 civil mediations, of which, about 250 were FLPSMP cases.

In addition to general comment responses regarding the FLPSMP, the mediators were asked to respond to the following specific issues: (a) Does the FLPSMP provide a fair, efficient and effective process of resolving medical malpractice disputes in avoidance of litigation?; (b) Do counsel for claimants find the program to be a fair, efficient and effective process to resolve medical malpractice disputes in avoidance of litigation?; (c) Do claimants find the FLPSMP to be a fair, efficient and effective process to resolve medical malpractice disputes in avoidance of litigation?; and (d) Are unrepresented claimants participating in the FLPSMP treated fairly and respectfully during the process. The selections available for response were: Strongly Agree, Agree, Neither Agree nor Disagree, Disagree, and Strongly Disagree. All but one mediator agreed or strongly agreed that claimants found that the program as a whole was a fair, efficient, and effective process to resolve medical malpractice disputes in avoidance of litigation. Almost all mediators agreed or strongly agreed that claimants'attorneys, represented claimants, and unrepresented claimants found the FLPSMP to be a fair, efficient and effective process to attempt to resolve their medical malpractice claims in avoidance of litigation.

Recommendations of the mediators for further improvement included providing more information prior to and at mediation regarding the purpose and intent of using FLPSMP at an early stage to resolve disputes. Mediators also opined that many of the attorneys for both sides appreciate the opportunity to settle the claim and learn more about potential defenses that could be raised by providers or health care facilities before investing significant time and resources in bringing a medical malpractice claim. Some mediators observed, however, that mediation for them is a challenge when some claimants' counsel come to mediation with a mindset that they are not interested in hearing about the medicine and defenses in the case, and will initially consider an information sharing mediation as a waste of time. The FLPSMP will pursue more avenues to obtain useful feedback to help enhance the FLPSMP.

\section{Conclusion}

FLPSMP's 13 years of experience with mandatory pre-suit mediation provides for a comprehensive COVID-19 pandemic-resistant blueprint to significantly reduce the time to resolve patient concerns and claims, improve patient safety, increase patient satisfaction, enhance provider-patient relationships, reduce unnecessary expense for patients and providers, and reduce insurance costs for providers and health care facilities that could otherwise be applied to instituting patient safety initiatives. The 13 years of demonstrated success of the FLPSMP should make it attractive for health care providers, health care facilities, and their insurers to consider adopting the essential elements of the FLPSMP not only in Florida, but nationally as well. The Uniform Mediation Act, for example, has been adopted in 13 states. In those states, both court-ordered and private, pre-suit / prelitigation mediations are protected under strict rules of confidentiality [38]. Although Florida has not adopted the Uniform Mediation Act, its current laws protect the confidentiality of the FLPSMP mediations. For states adopting the Uniform Mediation Act and other states, such as Florida, that protect the confidentiality of mediations not ordered by a court, the FLPSMP provides an adoptable design to empower providers and patients nation wide to appreciate the significant benefits experienced by UF Health.

Competing interests: The authors report no conflict of interest.

\section{References:}

1. Randall, Jenkins., Arlene, Smillov., \& Matthew, Goodwin., (2014). Mandatory Pre-suit Mediation: 5-Year Results of a Medical Malpractice Resolution Program, $33 \mathrm{~J}$ Healthc Risk Manag. 15, 18, available at https://onlinelibrary.wiley.com/ doi/10.1002/jhrm. 21138

2. Randall, J., Gregory, F., Kari, A., \& Brian, B. (2017). Mandatory Pre-Suit Mediation for Medical Malpractice: Eight -Year Results and Future Innovations. 35 Conflict Resol. Q. 73, 77, available athttps://onlinelibrary.wiley.com/doi/full/10.1002/ crq. 21194

3. Michelle, M. Mello et al, (2010). National Costs of the Medical Liability System, Health Aff. 29 (9) at 1569, available at https:// www.healthaffairs.org/doi/10.1377/hlthaff.2009.0807

4. 2019 Lawsuit Climate Survey, Rating the States, A Survey of the Fairness and Reasonableness of State Liability Systems, U.S. Chamber Institute for Legal Reform, at 10 - 22 (September 2019), available athttps://instituteforlegalreform.com/ research/2019-lawsuit-climate-survey-ranking-the-states/

5. Aon / ASHRM 2020 Hospital and Physician Professional Liability Benchmark Analysis, Aon, https://www.aon.com/riskservices/thought-leadership/2020-report-hospital-professionalliability-overvi.jsp (purchase required for full report).

6. Aon / ASHRM 2015 Hospital and Physician Professional Liability Benchmark Analysis 2015, Chicago: Aon (purchase required for full report)

7. Aon / ASHRM 2020, supra. 
8. U.S. Chamber Institute for Legal Reform 2019 Lawsuit Climate Survey, Ranking the States A Survey of the Fairness and Reasonableness of State Liability Systems (September 2019)https://instituteforlegalreform.com/wp-content/ uploads/2020/10/2019_Harris_Poll_State_Lawsuit_Climate_ Ranking_the_States.pdf

9. David, M. Studdert., et. al., (2006). Claims, Errors, and Compensation Payments in Medical Malpractice Litigation,New Eng. J. Med., 354 (19) at 2024. available at: https://www.nejm. org/doi/full/10.1056/nejmsa054479

10. See generally UF Health Education, available at https:// ufhealth.org/education and https://flbog.sip.ufl.edu

11. Randall, J., Gregory, F., Kari, A. \& Brian, B., (2017). Mandatory Pre-Suit Mediation for Medical Malpractice: Eight -Year Results and Future Innovations. 35 Conflict Resol. Q. 73, 75, available athttps://onlinelibrary.wiley.com/doi/full/10.1002/ crq. 21194

12. Fla. Stat. $\S \S 44.401-406$ (2021)

13. Fla. Stat. $\$ 44.405(1)(2021)$

14. Rules 10.100 - 10.130, Florida Rules for Certified and Court Appointed Mediators (2021), available athttps://www. floridasupremecourt.org/content/download/216759/file/rulescertified-court-appointed-mediators.pdf

15. Rules 10.200 - 10.690, Florida Rules for Certified and Court Appointed Mediators (2021), available at https://www. floridasupremecourt.org/content/download/216759/file/rulescertified-court-appointed-mediators.pdf

16. Fla. Stat. $\S 44.405(2)(2021)$

17. Fla. Stat. $\S 44.405(4)(a)(1)-(6)(2021)$

18. Fla. Stat. $\$ 44.107(2)(c)(2021)$

19. Randall, J., Gregory, F., Kari, A., \& Brian, B. (2017). Mandatory Pre-Suit Mediation for Medical Malpractice: Eight -Year Results and Future Innovations. 35 Conflict Resol. Q. 73, 75, available athttps://onlinelibrary.wiley.com/doi/full/10.1002/ crq. 21194

20. Fla. Stat. $\$ 766.108$ (2021)

21. Beth, H., \& Nettie, K., (2003). Communication Gaffes: A Root Cause of Malpractice Claims, Baylor U. Med. Ctr. Proc. 16, 157 - 161, available at https://www.ncbi.nlm.nih.gov/pmc/articles/ PMC1201002/

22. See Comm. on Patient Safety \& Quality Improvement, Am. Coll. of Obstetricians \& Gynecologists, Committee Opinion: Disclosure \& Discussion of Adverse Events (Dec. 2016) available athttps://www.acog.org/-/media/project/acog/acogorg/ clinical/files/committee opinion/articles/2016/12/disclosureand-discussion-of-adverse-events.pdf

23. Kevin J Hickey, (2021). Cong. Research Serv., LSB10443, The PREP Act and COVID-19: Limiting Liability for Medical Countermeasures 15 (Updated Sept. 23)

24. Richard, Ng., Lori, Rosen.Semlies., \& Jodi, V. Terranova., (2021). Updated! Medical Malpractice \& COVID-19: A Comparative Law Review (July 12), https:/www.wilsonelser. $\mathrm{com} /$ news_and_insights/legal_analysis/3786-updated medical_malpractice_covid-19_a_comparative
25. Diane Robinson \& Sarah Gibson, (2021). Pandemic Caseload Highlights: Court Filings and Dispositions 2019 - 2020, National Center for State Courts Court Statistics Project (March 22), https://www.courtstatistics.org/ data/assets/pdf file/0022/61519/2020_4Q_pandemic.pdf.

26. Randall, J., Arlene, S., \& Matthew, G., (2014). Mandatory Pre-suit Mediation: 5-Year Results of a Medical Malpractice Resolution Program,J Healthc Risk Manag. 33, 15-18, available at https://onlinelibrary.wiley.com/doi/10.1002/jhrm.21138

27. Ralph, P., Catherine, H. and Thomas, R., (2007). Following the Script, An Empirical Analysis of Court-Ordered Mediation of Medical Malpractice Cases, Journal of Dispute Resolution; at $106 \mathrm{https} / / /$ scholarship.law.duke.edu/cgi/viewcontent.cgi?articl $\mathrm{e}=2506$ \& context $=$ faculty_scholarship

28. Aon / ASHRM 2020, supra.

29. Fla. Stat. $§ 766.102(5)(a)$

30. See, Estate of McCall v. United States, 134 So. 3d 894 (Fla. 2014) (holding that the $\$ 766.118$, Fla. Stat.non-economic damages caps for medical malpractice are unconstitutional).

31. Compiled from data contained in the closed claims sections of Aon reports for calendar years 2013 through 2020

32. The Aon data for claims expenses for Florida as a whole and the nation for calendar year 2020 will be in its 2021 report scheduled for November 2021. Accordingly, only the 2020 expense data for FLPSMP is shown in Figure 3.

33. Philip G. Peters Jr., (2009). Twenty Years of Evidence on the Outcomes of Malpractice Claims, Clin Orthop Relat Res 467:352 Abstract, available at https://www.ncbi.nlm.nih.gov/ pmc/articles/PMC2628515/

34. See, The Hospital Value-Based Purchasing (VBP) Program, Centers for Medicare and Medicaid Services (2021), https://www.cms.gov/Medicare/Quality-Initiatives-PatientAssessment-Instruments/Value-Based-Programs/HVBP/ Hospital-Value-Based-Purchasing

35. Randall, J., Gregory, F., Kari, A. \& Brian, B., (2017). Mandatory Pre-Suit Mediation for Medical Malpractice: Eight -Year Results and Future Innovations. Conflict Resol. Q., 35, 73-85, available athttps://onlinelibrary.wiley.com/doi/full/10.1002/ crq. 21194

36. Orna Rabinovich-Einy, (Summer 2011). Escaping the shadow of Malpractice Law. Law \& Contmp. Probs, 74, at 241, available athttps://scholarship.law.duke.edu/cgi/viewcontent. cgi?article $=1641 \&$ context $=$ lcp

37. Id. at 241, See also, Randall Jenkins, Gregory Fireston, Kari Aasheim \& Brian Boelens. Mandatory Pre-Suit Mediation for Medical Malpractice: Eight -Year Results and Future Innovations. 35 Conflict Resol. Q. 73 (2017), available athttps:// onlinelibrary.wiley.com/doi/full/10.1002/crq.21194

38. See Uniform Law Commission https://www.uniformlaws.org/ committees/community-home?CommunityKey $=45565 \mathrm{a} 5 \mathrm{f}$ 0c57-4bba-bbab-fc7de9a59110; https://www.uniformlaws. org/HigherLogic/System/DownloadDocumentFile. ashx? DocumentFileKey=9b244b42-269c-769e-9f89590 ce $048 \mathrm{~d} 0 \mathrm{dd} \&$ forceDialog $=0$ 